\title{
Environmental performance evolution of municipal solid waste management by life cycle assessment in Hangzhou, China
}

\author{
Zhaozhi Zhou ${ }^{\mathrm{a}}$, Yuanjun Tang ${ }^{\mathrm{a}}$, Jun Dong ${ }^{\mathrm{b}}$, Yong Chi ${ }^{\mathrm{a}, *}$, Mingjiang $\mathrm{Ni}^{\mathrm{a}}$, Nan $\mathrm{Li}^{\mathrm{a}}$, Yongfang Zhang ${ }^{\mathrm{c}}$ \\ a State Key Laboratory of Clean Energy Utilisation, Zhejiang University, Hangzhou, China \\ ${ }^{b}$ Centre RAPSODEE, Ecole des Mines Albi, Campus Jarlard, 81013 Albi Cedex, France \\ ${ }^{\mathrm{c}}$ Hangzhou Municipal Solid Waste Disposal Supervision Center, Hangzhou, China
}

\section{A R T I C L E I N F O}

\section{Keywords:}

Waste management

Source-separated collection

Evolution

Life cycle assessment

Environmental impact

\begin{abstract}
A B S T R A C T
There is a significant increase in the volume of Municipal Solid Waste (MSW) that is being generated across the world. Faced with this challenge and the associated environmental issues, MSW management (MSWM) in Hangzhou, China has made various positive changes in order to adapt. During the last 10 years, MSW sourceseparated collection was launched, which was accompanied by estimations of a new waste-to-energy (incineration) plant and food waste separate treatment methods. The aim of this study is to investigate the related evolution of the environmental performance of MSWM system in Hangzhou from 2007 to 2016 by using life cycle assessment (LCA). LCA is a scientific tool to quantify factors such as environmental impacts from a life cycle perspective and provides valuable inputs to decision-makers, thus leading to proper strategy determination. Results illustrate that the annual environmental performance has an overall downward trend with some minor fluctuations. The MSWM system in 2010 had the lowest weighted result of $0.0349 \mathrm{PE} / \mathrm{t}-\mathrm{MSW}$ due to the highest incineration rate and implementation of source-separated collection. Incineration shows better environmental performance than landfill, while source-separated collection can benefit the MSWM. While the importance of source-separated collection is significant, it is also essential to concentrate on the food waste treatment technology. It is suggested that anaerobic digestion (AD) can be considered as a primary option for food waste treatment.
\end{abstract}

\section{Introduction}

The amount of municipal solid waste (MSW) in China has increased rapidly in the last few decades and China now is the largest MSW generator in the world (Zhou et al., 2018). In 2015, the annual generated MSW has reached 191.4 million tonnes, with a ten-year cumulative growth rate of $122.9 \%$ (CSYCC, 2016). The increasing amount and complex components of MSW impose the evolution of municipal solid waste management (MSWM). Source-separated collection is considered as a desirable option to achieve the principle of "reducing quantity" "harmless" "reclamation" for waste management (Han and Zhang, 2017; Ma et al., 2017; Ripa et al., 2017). In 2017, an implementation plan regarding MSW source-separated collection was launched by China's national development and reform commission. At present, source-separated collection has been implemented in many cities, and several corresponding regulations and facilities have been established. New policies and standards on waste treatment enable the formal and scientific management. In general, various strategies aiming at enhancing MSWM have been adopted in the last few years, but their realistic effects on environmental improvement need to be examined.

To assess the environmental performance scientifically, life cycle assessment (LCA) is widely adopted. LCA is a systematic methodology considering all inputs and outputs of materials and energy 'from cradle to grave' (ISO, 2006a,b; Jeswani and Azapagic, 2016). LCA can quantify the environmental impacts and support the decision-makers to identify the appropriate strategy.

Until now, LCA has been conducted in various waste management systems. Dong et al. (2014) compared the incineration, landfill with and without energy recovery and concluded the incineration was more suitable for MSWM. Havukainen et al. (2017) suggested that refuse derived fuel (RDF) production could improve the environmental impacts on waste incineration based on LCA results. Advanced WtE technologies, for instance pyrolysis, gasification and plasma, also have been examined by LCA in recent years. Evangelisti et al. (2015) utilized LCA to compare the two-stage gasification and plasma with conventional WtE technology. Arena et al. (2015) evaluated a vertical shaft 
gasifier coupled with direct melting and suggestions for improvement in technological solutions were put forward for further development. Pyrolysis-gasification was also modeled and assessed in toxic impacts and non-toxic impacts (Zaman, 2013).

Based on the WtE case-study LCA scenarios from 1995 to 2013, a concrete overview of assumptions and modeling choices for WtE was provided and some practical recommendations were put forward for the further LCA study (Astrup et al., 2015). Zhou et al. (2018) also summarized the ranges of the environmental results of different WtE techniques worldwide. Othman et al. (2013) analyzed the LCA scenarios in Asian MSW management systems and the results were used as a reference for decisions on strategies for waste management.

However, most researches focus on the environmental impacts of waste treatment technologies, but little attention has been paid to the evolution of the MSWM system with time. Ibáñez-Forés et al. (2018) assessed the temporal evolution of the environmental performance of MSWM system in João Pessoa, Brazil, and focused on the effect of doorto-door selective collection of recyclable waste; however, its evolution was mainly caused by the change of MSW composition and the population served by each sorting unit; besides, recycle and landfill were the only treatment methods in the system. Nowadays, WtE technologies play an important role in MSWM (Zhou et al., 2018). The integrated MSWM system with WtE technologies is more complex and its environmental performance evolution can reflect meaningful results for decision-makers.

The goal of this study is to analyze the environmental performance evolution of integrated MSWM system during the last decade (i.e., from 2007 to 2016) in Hangzhou, China. The evolution of MSWM is modeled and annual MSWM strategies are included. The changes of environmental performance with each passing year are evaluated by LCA. The results could give a better understanding of the environmental performance of the MSWM system and reflect effects of MSWM strategies. Source-separated collection and food waste treatment technologies are further analyzed in sensitivity analysis and the results can be served as a support for the future MSWM development.

\section{MSWM system in Hangzhou}

Hangzhou, one of the most developed coastal cities with advanced economy and dense population in China, is chosen for this study. Hangzhou has an urban area of $16,596 \mathrm{~km}^{2}$ and a population of 9.18 million (HSYCC, 2017), and its GDP reached 1.17 trillion CNY in 2016, which ranks the tenth in China. However, like the most cities in China, Hangzhou faces the MSW treatment challenges. Fig. 1 shows the amount of MSW generated and treatment from 2007 to 2016 in

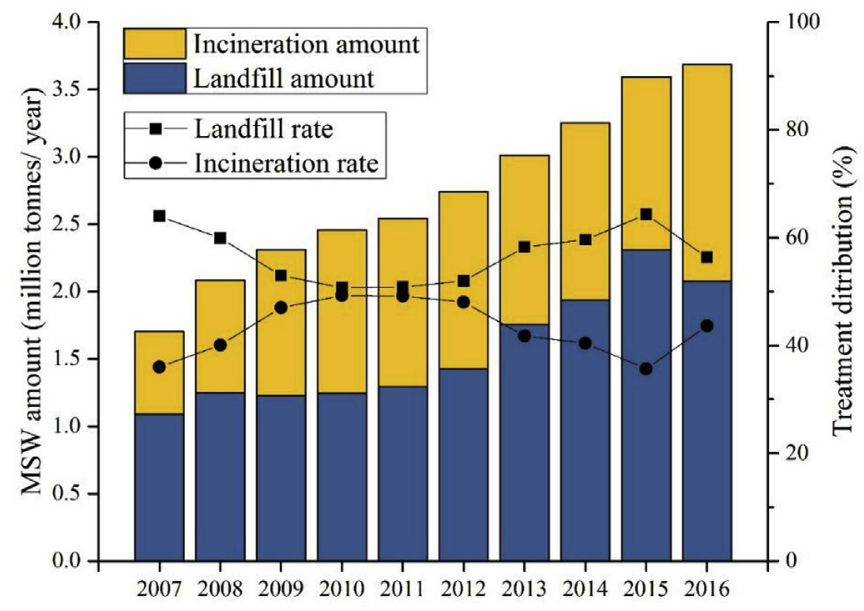

Fig. 1. Amount of MSW generated and treatment distribution in Hangzhou from 2007 to 2016 (HMSWDSC, 2016).
Table 1

MSW treatment plants at the end of 2016 in Hangzhou.

\begin{tabular}{|c|c|c|c|c|}
\hline Name & Technology & $\begin{array}{l}\text { Energy } \\
\text { recovery }\end{array}$ & $\begin{array}{l}\text { Capacity (t/ } \\
\text { d) }\end{array}$ & Start date \\
\hline Tianziling & Landfill & Electricity & - & Jan. 2007 \\
\hline $\begin{array}{l}\text { Tianziling (for } \\
\text { food waste) }\end{array}$ & $\begin{array}{l}\text { Anaerobic } \\
\text { digestion }\end{array}$ & Electricity & 200 & Jun. 2014 \\
\hline Binjiang & $\begin{array}{l}\text { Incineration } \\
\text { (Grate) }\end{array}$ & Electricity & 600 & Oct. 2004 \\
\hline Yuhang & $\begin{array}{l}\text { Incineration } \\
\text { (fluidized bed) }\end{array}$ & Electricity & 600 & Oct. 1998 \\
\hline Qiaosi & $\begin{array}{l}\text { Incineration } \\
\text { (fluidized bed) }\end{array}$ & Electricity & 800 & Jun. 2002 \\
\hline Xiaoshan & $\begin{array}{l}\text { Incineration } \\
\text { (fluidized bed) }\end{array}$ & Electricity & 1200 & Jul. 2007 \\
\hline Jiangdong & $\begin{array}{l}\text { Incineration } \\
\text { (fluidized bed) }\end{array}$ & Electricity & 1200 & Dec. 2015 \\
\hline
\end{tabular}

Hangzhou. Hangzhou generated 1,703,450 tonnes and 3,684,946 tonnes in 2007 and 2016 respectively, with an annual growth rate of 9.0\% (HMSWDSC, 2016). Landfill was the main MSW treatment method, while incineration got much attention and developed rapidly these years. However, the amount of MSW generated grew quickly while the capacity of incineration factories was limited. Therefore, the MSW incineration rate decreased from 2011 to 2015 after the rise from 2007 to 2010. A new waste-to-energy (incineration) plant was put into operation in December 2015 and the incineration rate grew sharply from 2015 to 2016. At the end of 2016, there were five MSW incineration plants and one landfill plants (see in Table 1).

The physical composition of mixed waste generated in Hangzhou is given in Table 2. MSW generated in Hangzhou has high moisture content due to its high proportion of food waste. As shown in Table 2, the food waste accounts for $55.6 \%$ of the total mixed waste. Besides, the mixed waste has rather low LHV (low heating value), which effects the incineration process and energy recovery. Therefore, the separate collection and treatment of food waste are essential.

Hangzhou is the pioneer regarding MSW source-separated collection in China and started it in 2010. Food waste is separately collected and then the mixed waste after source-separated collection is sent to landfill or incineration. After separate collection, the mixed waste has higher LHV and is suitable for effective incineration. The food waste is sent for separate landfill in Tianziling. For the purpose of better food waste management, an anaerobic digestion (AD) pilot project was put into operation in Tianziling in June 2014. In Hangzhou, most recyclables, for instance cardboard, plastic and metal bottles, are collected and sold by residents before the formal collection organized by the government.

Table 2

Physical composition of mixed waste before and after source-separation in Hangzhou (HMSWDSC, 2016).

\begin{tabular}{lll}
\hline Composition & $\begin{array}{l}\text { Mixed waste before source- } \\
\text { separated collection }\end{array}$ & $\begin{array}{l}\text { Mixed waste after source- } \\
\text { separated collection }\end{array}$ \\
\hline Food waste & $55.79 \%$ & $41.06 \%$ \\
Dust & $3.50 \%$ & $4.67 \%$ \\
Bricks & $1.85 \%$ & $2.47 \%$ \\
Paper & $12.14 \%$ & $16.19 \%$ \\
Plastics & $13.67 \%$ & $18.23 \%$ \\
Rubber & $1.37 \%$ & $1.82 \%$ \\
Textiles & $4.12 \%$ & $5.50 \%$ \\
Glass & $2.81 \%$ & $3.75 \%$ \\
Metals & $2.49 \%$ & $3.32 \%$ \\
Wood & $1.53 \%$ & $2.05 \%$ \\
Others & $0.71 \%$ & $0.94 \%$ \\
Moisture (wt.\%) & $62.05 \%$ & $59.40 \%$ \\
LHV (kJ/kg) & 5551.81 & 6402.42 \\
\hline
\end{tabular}

a The data are obtained from the average of MSW compositions from 2012 to 2016 


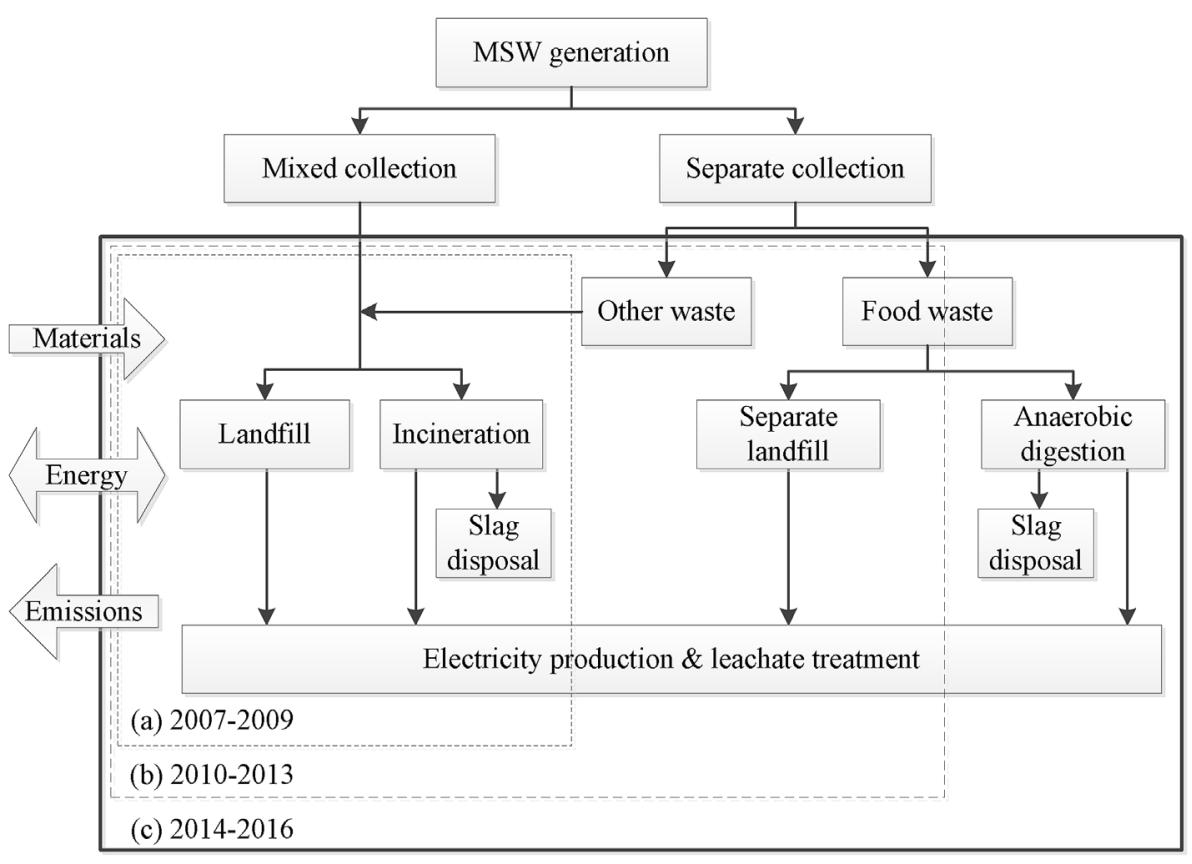

Fig. 2. System boundary of the study: (a) during 2007-2009, 100\% mixed collection (dotted box); (b) during 2010-2013, 25\% source-separated collection and food waste was treated by separate landfill (dashed box); (c) during 2014-2016, 25\% source-separated collection and food waste was treated by $\mathrm{AD}$ and separate landfill (solid box).
Thus, only a small proportion of recyclables flow into the municipal collection system. This informal collection is common in China (Steuer et al., 2017; Zhang and Wen, 2014). Therefore, source-separated collection for recyclables is not considered in this study.

\section{Methodology}

According to ISO 14040 standards, the LCA consists of four phases: goal and scope definition, life cycle inventory (LCI), life cycle impact assessment (LCIA), and interpretation (ISO, 2006a,b).

\subsection{Goal and scope definition}

This study aims to evaluate the environmental impact evolution of MSWM system in Hangzhou, China over the last decade. Fig. 2 shows system boundary of the study and the system is divided into three periods: (a) during 2007-2009, MSW was unsegregated and was sent for landfill or incineration (in dotted box); (b) during 2010-2013, part of food waste was separately collected and transported for separate landfill, while the rest mixed waste was diverted for landfill or incineration (in dashed box); (c) during 2014-2016, 73 thousand tonnes of food waste was treated by AD (36.5 thousand tonnes in 2014), and the rest was sent to separate landfill (in solid box). The system involves 6 MSW treatment scenarios and the information of the scenarios is illustrated in Table 3.

To evaluate the environmental impacts, some assumptions are made:

(1) The fractions of MSW composition are assumed to keep same in these ten years, since the variation of MSW compositions in

Table 3

The description of treatment scenarios.

\begin{tabular}{lll}
\hline Scenario & Method & Waste type \\
\hline Scenario 1.1 & Landfill & Mixed waste before separate collection \\
Scenario 1.2 & Landfill & Mixed waste after separate collection \\
Scenario 2.1 & Incineration & Mixed waste before separate collection \\
Scenario 2.2 & Incineration & Mixed waste after separate collection \\
Scenario 3.1 & Landfill & Food waste \\
Scenario 3.2 & Anaerobic digestion & Food waste
\end{tabular}

Hangzhou is little (HMSWDSC, 2016). The deviation caused by this assumption can be ignored realizing the fact that the aim is focused on evolution of MSWM system.

(2) According to the Hangzhou Municipal Solid Waste Disposal Supervision Center, the source-separated collection efficiency reached 25\% (Dong et al., 2013). The efficiency is assumed to keep $25 \%$ in the assessment and the effect of source-separated collection efficiency is discussed in sensitivity analysis. Thus, Fig. 3 presents the evolution of MSW treatment distribution in this study and Table A.1SM (available as supplementary available online) illustrates the associated MSW mass (HMSWDSC, 2016).

(3) Collection process and transportation from collection point to treatment plant are not considered in this system boundary. However, disposal of bottom ash and fly ash is the necessary part of incineration. Thus, transportation for bottom ash and fly ash is contained in the system boundary.

(4) Electricity produced is sent to the electricity grid and is assumed to displace same amount of electricity produced from China's mixed power grid.

(5) Because of the unavailable of investigation data, emissions to the soil are assumed not to be contained in this study, and emissions to the water only consider the $\mathrm{NH}_{3}-\mathrm{N}$ and T-P in leachate.

\subsection{Inventory analysis}

Collecting and establishing inventory data is one of the most laborand time-intensive work. The inventory includes the material flow and energy flow that cross the system boundary.

\subsubsection{Landfill}

More than half of the MSW in Hangzhou is sent to the Tianziling for landfill. Intergovernmental Panel on Climate Change (IPCC) proposed the calculation method to estimate the $\mathrm{CH}_{4}$ emission from landfill. The equations are listed as follows (IPCC, 2006):

$\mathrm{CH}_{4}$ Emissions $=\left[\sum_{x} \mathrm{CH}_{4}\right.$ generated $\left._{x, T}-R_{T}\right] \times\left(1-\mathrm{OX}_{T}\right)$

$\mathrm{CH}_{4}$ generated $_{x, T}=\mathrm{DDOC}_{m, x} \times F \times 16 / 12$

$D D O C_{m, x}=W_{x} \times D O C_{x} \times D O C_{f} \times M C F$ 


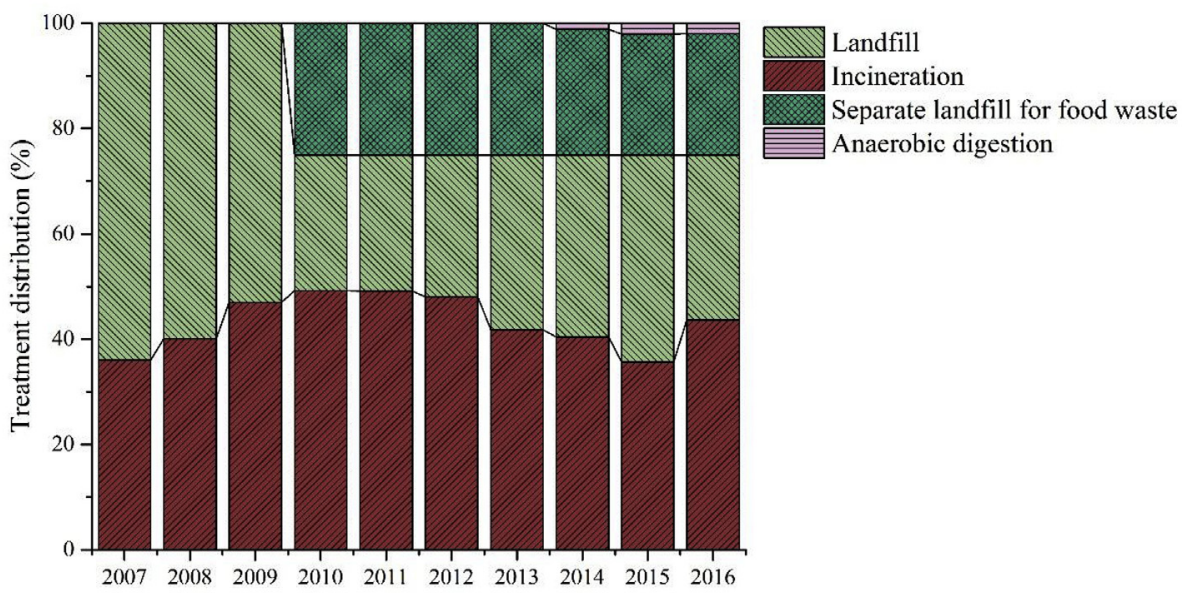

Fig. 3. The evolution of MSW treatment distribution in this study during 2007-2016.

$\mathrm{CH}_{4}$ Emissions: $\mathrm{CH}_{4}$ emitted in year $\mathrm{T}(\mathrm{Gg})$;

$\mathrm{CH}_{4}$ generated $_{x, T}: \mathrm{CH}_{4}$ generated from waste type $\mathrm{x}$ in year $\mathrm{T}(\mathrm{Gg})$; $R_{T}$ : Recovered $\mathrm{CH}_{4}$ in year $\mathrm{T}(\mathrm{Gg})$;

$O X_{T}$ : Oxidation factor in year $\mathrm{T}(\%)$;

$D D O C_{m, x}$ : Mass of decomposable degradable organic carbon in waste type $\mathrm{x}(\mathrm{Gg})$;

$F$ : Fraction by volume of $\mathrm{CH}_{4}$ in landfill gas (\%);

$W_{x}$ : Mass of waste type $\mathrm{x}$ deposited $(\mathrm{Gg})$;

$D O C_{x}$ : Fraction of degradable organic carbon in waste type $\mathrm{x}(\mathrm{Gg} \mathrm{C}$ ) $\mathrm{Gg}$ waste);

$D O C_{f}$ : Fraction of degradable organic carbon that can decompose;

$M C F: \mathrm{CH}_{4}$ correction factor.

Based on IPCC default value, the $\mathrm{CH}_{4}$ oxidation factor and correction factor is set at 0.1 and 0.77 (IPCC, 2006). The carbon content of different waste types is summarized in Table A.2SM and the $\mathrm{DOC}_{\mathrm{f}}$ is assumed to be 1 . In Tianziling landfill, $54.5 \%$ volume of the landfill gas is $\mathrm{CH}_{4}\left(\mathrm{CO}_{2} 45 \%\right)$ and $65 \%$ of generated $\mathrm{CH}_{4}$ is recovered and converted into electricity at an efficiency of $39.1 \%$ by a gas engine (Dong et al., 2014). A set of wastewater treatment equipment is installed and leachate is directly discharged to the city's sewage treatment system after purification.

\subsubsection{Incineration}

The data of incineration are mainly from the long-term on-site visit to a $1200 \mathrm{t} /$ day incineration plant utilized fluidized bed technology and Hangzhou municipal solid waste disposal supervision center. According to the MSW composition, LHV and the fossil carbon content of MSW are calculated to be $5551.81 \mathrm{MJ} / \mathrm{t}-\mathrm{MSW}$ and $11.7 \%$. Coal, with LHV of $21 \mathrm{MJ} / \mathrm{kg}$ and fossil carbon content of $44.5 \%$, is taken as an auxiliary fuel at a ratio of $50 \mathrm{~kg} / \mathrm{t}-\mathrm{MSW}$. The electricity generation efficiency is estimated to be $23 \%$. Among the generated electricity, $80 \%$ is sent to power grid and $20 \%$ is for self-consumption. Advanced air pollution control system is equipped for flue gas purification and its input materials are illustrated in Table 4. Bottom ash and fly ash, accounting for $17 \%$ and $3 \%$ of total mass, are solidified by cement and sent for special landfill $45.8 \mathrm{~km}$ away from the incineration (Dong et al., 2014). Sourceseparated collection changes the LHV and fossil carbon proportion of the mixed MSW and leads to the variation of electricity generation and $\mathrm{CO}_{2}$ emissions.

\subsubsection{Food waste treatment}

The food waste is separately collected and sent to Tianziling for landfill. The calculation method regarding $\mathrm{CH}_{4}$ generation is similar as that of mixed waste landfill. In June 2014, an AD pilot project with a capacity of $200 \mathrm{t} /$ day was put into trial operation in Tianziling and part of the food waste was treated by AD. The yield of biogas is estimated to be $108 \mathrm{Nm}^{3}$ /tonne food waste, with $\mathrm{CH}_{4}$ content of $63 \%$ volume. $\mathrm{CH}_{4}$

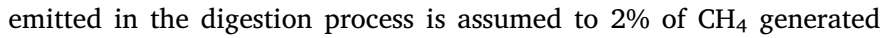
(Fruergaard and Astrup, 2011). The AD slag, with moisture content of $80 \%$, accounts for $15 \%$ of total mass. However, the slag is not suitable for composting due to high salt content, and hence, the slag is treated by landfill after dewatering. Since the AD facility is only in trial operation and its data cannot be obtained, the energy consumption and emission data are from Danish plants based on the literatures (Fruergaard and Astrup, 2011; Jungbluth et al., 2007).

\subsubsection{Life cycle inventory}

In this study, the inventory data are obtained from long-term on-site visit of the treatment plants and reports by Hangzhou MSW disposal supervision center. Background data on raw material production and electricity production are from Gabi 8.0 software database (Thinkstep, 2018). The life cycle inventory of each scenario is summarized in Table 4.

\subsection{Impact assessment methodology}

Gabi 8.0 software and the EDIP 97 are adopted for environmental impact assessment (Thinkstep, 2018). Danish EDIP 97 is in accordance with the requirements of the ISO framework and widely recognized by LCA-researchers (Dong et al., 2014). According to EDIP97, global warming potential (GWP), acidification potential (AP), nutrient enrichment potential (NEP), photochemical oxidant potential (POP) are considered as the environmental impact categories in this study. The impact assessment includes characterization, normalization and weighting steps.

\section{Results and discussion}

\subsection{Environmental results of each scenario}

The environmental results caused by the study scenarios are presented as Fig. 4, including the contributions of main stages to each impact category. For a reasonable comparison, one tonne of corresponding waste is taken out as the basis. The main stages are divided into avoided electricity, direct emissions, input materials and energy. The negative value means a benefit to the relevant environmental impact.

The main contribution substances for GWP are $\mathrm{CH}_{4}, \mathrm{CO}_{2}$ and $\mathrm{N}_{2} \mathrm{O}$. Biogenic $\mathrm{CO}_{2}$ emission is not considered as it is carbon neutral to atmosphere, but will be further analyzed in the "Sensitivity analysis" (Dong et al., 2013). As shown in Fig. 4a, greenhouse gas emissions are 
Table 4

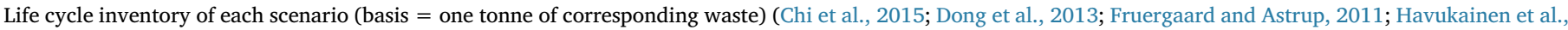
2017; Jungbluth et al., 2007).

\begin{tabular}{|c|c|c|c|c|c|c|c|}
\hline \multirow[t]{2}{*}{ 1t-MSW } & \multirow[t]{2}{*}{ Unit } & \multicolumn{6}{|l|}{ Scenario } \\
\hline & & 1.1 & 1.2 & 2.1 & 2.2 & 3.1 & 3.2 \\
\hline \multicolumn{8}{|l|}{ Input } \\
\hline Diesel for mechanical operation & $\mathrm{kg}$ & 1.07 & 1.07 & 1.96 & 1.96 & 1.07 & 1.07 \\
\hline Diesel for transportation of fly ash and bottom ash & $\mathrm{kg}$ & 0 & 0 & 0.27 & 0.27 & 0 & 0 \\
\hline Electricity & kWh & 1.56 & 1.56 & 83.99 & 89.10 & 1.56 & 49.48 \\
\hline HDPE & $\mathrm{kg}$ & 0.45 & 0.45 & 0 & 0 & 0.45 & 0.10 \\
\hline Limestone & $\mathrm{kg}$ & 0.77 & 0.77 & 0 & 0 & 0.77 & 0 \\
\hline Clay & $\mathrm{kg}$ & 59.7 & 59.7 & 0 & 0 & 59.7 & 0 \\
\hline $\mathrm{NaCl}$ & $\mathrm{kg}$ & 0.37 & 0.37 & 0 & 0 & 0.37 & 0 \\
\hline Calcium hydroxide & $\mathrm{kg}$ & 0 & 0 & 18.14 & 18.14 & 0 & 0 \\
\hline Ammonia water & $\mathrm{kg}$ & 0 & 0 & 8.94 & 8.94 & 0 & 0 \\
\hline Coal & $\mathrm{kg}$ & 0 & 0 & 50 & 50 & 0 & 0 \\
\hline Lubricating oil & $\mathrm{kg}$ & 0 & 0 & 0.04 & 0.04 & 0 & 0 \\
\hline Cement & $\mathrm{kg}$ & 0 & 0 & 14.70 & 14.70 & 0 & 0 \\
\hline \multicolumn{8}{|l|}{ Direct emissions to air } \\
\hline $\mathrm{CH}_{4}$-bio & $\mathrm{kg}$ & 26.98 & 27.17 & 0.00 & 0.00 & 18.85 & 0.97 \\
\hline $\mathrm{CO}_{2}$-fossil & $\mathrm{kg}$ & 0 & 0 & 509.68 & 652.38 & 0 & 0 \\
\hline $\mathrm{CO}_{2}$-bio & $\mathrm{kg}$ & 488.04 & 491.58 & 562.23 & 566.31 & 498.16 & 547.33 \\
\hline $\mathrm{N}_{2} \mathrm{O}$ & $\mathrm{kg}$ & 0 & 0 & 0.05 & 0.05 & 0 & 0 \\
\hline $\mathrm{CO}$ & $\mathrm{kg}$ & 0.07 & 0.07 & 0.20 & 0.20 & 0.07 & 0.12 \\
\hline NH3 & $\mathrm{kg}$ & 0.08 & 0.08 & 0 & 0 & 0.08 & 0 \\
\hline $\mathrm{H} 2 \mathrm{~S}$ & $\mathrm{~kg}$ & 0.17 & 0.17 & 0 & 0 & 0.17 & 0 \\
\hline VOCs & $\mathrm{kg}$ & 0.05 & 0.05 & 0 & 0 & 0.05 & 0.11 \\
\hline $\mathrm{HCl}$ & $\mathrm{kg}$ & 0 & 0 & 0.023 & 0.023 & 0 & 0 \\
\hline $\mathrm{HF}$ & $\mathrm{kg}$ & 0 & 0 & 0.009 & 0.009 & 0 & 0 \\
\hline $\mathrm{NO}_{\mathrm{x}}$ & $\mathrm{kg}$ & 0.06 & 0.06 & 0.48 & 0.48 & 0.06 & 0.15 \\
\hline $\mathrm{SO}_{2}$ & $\mathrm{~kg}$ & 0.03 & 0.03 & 0.09 & 0.09 & 0.03 & 0 \\
\hline PM10 & $\mathrm{kg}$ & 0 & 0 & 0.094 & 0.094 & 0 & 0 \\
\hline PCDD/DFs & $\mathrm{kg}$ & 0 & 0 & $2.40 \mathrm{E}-09$ & $2.40 \mathrm{E}-09$ & 0 & 0 \\
\hline Mercury & $\mathrm{kg}$ & $3.41 \mathrm{E}-08$ & $3.41 \mathrm{E}-08$ & $2.16 \mathrm{E}-05$ & $2.16 \mathrm{E}-05$ & $3.41 \mathrm{E}-08$ & 0 \\
\hline Lead & $\mathrm{kg}$ & 0 & 0 & $9.62 \mathrm{E}-06$ & $9.62 \mathrm{E}-06$ & 0 & 0 \\
\hline Cadmium & $\mathrm{kg}$ & 0 & 0 & $9.62 \mathrm{E}-06$ & $9.62 \mathrm{E}-06$ & 0 & 0 \\
\hline \multicolumn{8}{|l|}{ Direct emissions to water } \\
\hline $\mathrm{NH}_{3}-\mathrm{N}$ & $\mathrm{kg}$ & 0.2 & 0.2 & $3.27 \mathrm{E}-04$ & $3.27 \mathrm{E}-04$ & 0.2 & 0.2 \\
\hline T-P & $\mathrm{kg}$ & $2.38 \mathrm{E}-03$ & $2.38 \mathrm{E}-03$ & $1.62 \mathrm{E}-05$ & $1.62 \mathrm{E}-05$ & $2.38 \mathrm{E}-03$ & $2.38 \mathrm{E}-03$ \\
\hline \multicolumn{8}{|l|}{ Output } \\
\hline Electricity & kWh & 217.05 & 218.62 & 419.95 & 474.06 & 244.99 & 260.10 \\
\hline Leachate & $\mathrm{kg}$ & 200 & 192.05 & 60 & 57.62 & 223.85 & 223.85 \\
\hline
\end{tabular}

the main contribution to GWP results. Landfill scenarios (scenarios 1.1 and 1.2) have the worst performance of GWP due to the high amount of $\mathrm{CH}_{4}$ emitted, which accounts for high level of GWP equivalent factor. However, for incineration scenarios (scenarios 2.1 and 2.2), more electricity is produced and more avoided GWP from electricity production can be obtained. Separate landfill of food waste (scenario 3.1) has a better performance due to less $\mathrm{CH}_{4}$ released. $\mathrm{AD}$ (scenario 3.2) is the only scenario that has a negative value and much better than other scenarios. This is mainly because of the decrease in emitted $\mathrm{CH}_{4}$ by enclosed type of $\mathrm{AD}$ reactor and high $\mathrm{CH}_{4}$ recovery rate.

In view of AP, all the scenarios have the negative values and benefit the environment. The burden from acid gases, for instance $\mathrm{H}_{2} \mathrm{~S}, \mathrm{HCl}$, $\mathrm{SO}_{2}, \mathrm{NO}_{\mathrm{x}}$, and so on, is well counterbalanced by the offsets of electricity production. Because of good performance on "avoid electricity", scenario 2.2 has the lowest value of AP.

$\mathrm{NH}_{3}-\mathrm{N}$ and T-P in leachate are main contributing elements for NEP and leachate pollutants from landfill and food waste treatment have higher concentration. More $\mathrm{NO}_{\mathrm{x}}$ is discharged during incineration and $\mathrm{NO}_{\mathrm{x}}$ is another main contributor to NEP, but its NEP effect is offset by the electricity generation. Thus, regarding NEP, scenario 2.2 has the only negative value.

VOCs, $\mathrm{CO}$ and $\mathrm{CH}_{4}$ are main source causing POP. POP for high NOx is chosen for the environment assessment in Hangzhou (Dong et al., 2014; Du et al., 2011). Landfill scenarios have the highest POP, mainly owing to the emission of $\mathrm{CH}_{4}$ and VOCs during landfill. Negative values appear in both incineration scenarios due to the recovered energy and the control the POP emission.
Source-separated collection changes the composition of MSW and affects the environmental impacts of the waste treatment technologies. The environmental impacts of mixed MSW landfill before and after source-separated collection almost remain unchanged. However, source-separated collection can reduce the amount of mixed MSW deposited by landfill, which is equal to the amount of food waste by separate treatment. Compared to scenario 1.2, scenario 3.1 could reduce the GWP, AP, NEP and POP by $45.9 \%, 33.4 \%, 11.7 \%$ and $36.8 \%$ respectively. The main reason is that separate landfill for food waste produces more avoided emissions by electricity generation. The environmental performance can be better if the food waste is treated by AD. Regarding incineration for mixed waste, the AP, NEP and POP after source-separated collection decrease $25.5 \%, 440.7 \%$ and $18.2 \%$ respectively, while GWP increases $36.5 \%$. It is because the source-separated collection increases fossil carbon content and LHV of MSW: higher LHV results in a larger amount of electricity production and it can improve all the impact results; for incineration, $\mathrm{CO}_{2}$ emitted by fossil carbon combustion is the main contributor to GWP and the amount of added "direct emissions" after source-separated collection is higher than the one of added "avoided electricity", leading to the increase of burden of GWP.

Regarding the MSWM system with $50.7 \%$ for landfill and $49.3 \%$ for incineration in 2010, source-separated collection saves $2.0 \%, 23.6 \%$, $41.3 \%$ and $33.0 \%$ impacts of GWP, AP, NEP and POP for treating one tonne of MSW.

Fig. 5 illustrates the weighted environmental impact results of each scenario. Landfill scenarios show the worst environmental 

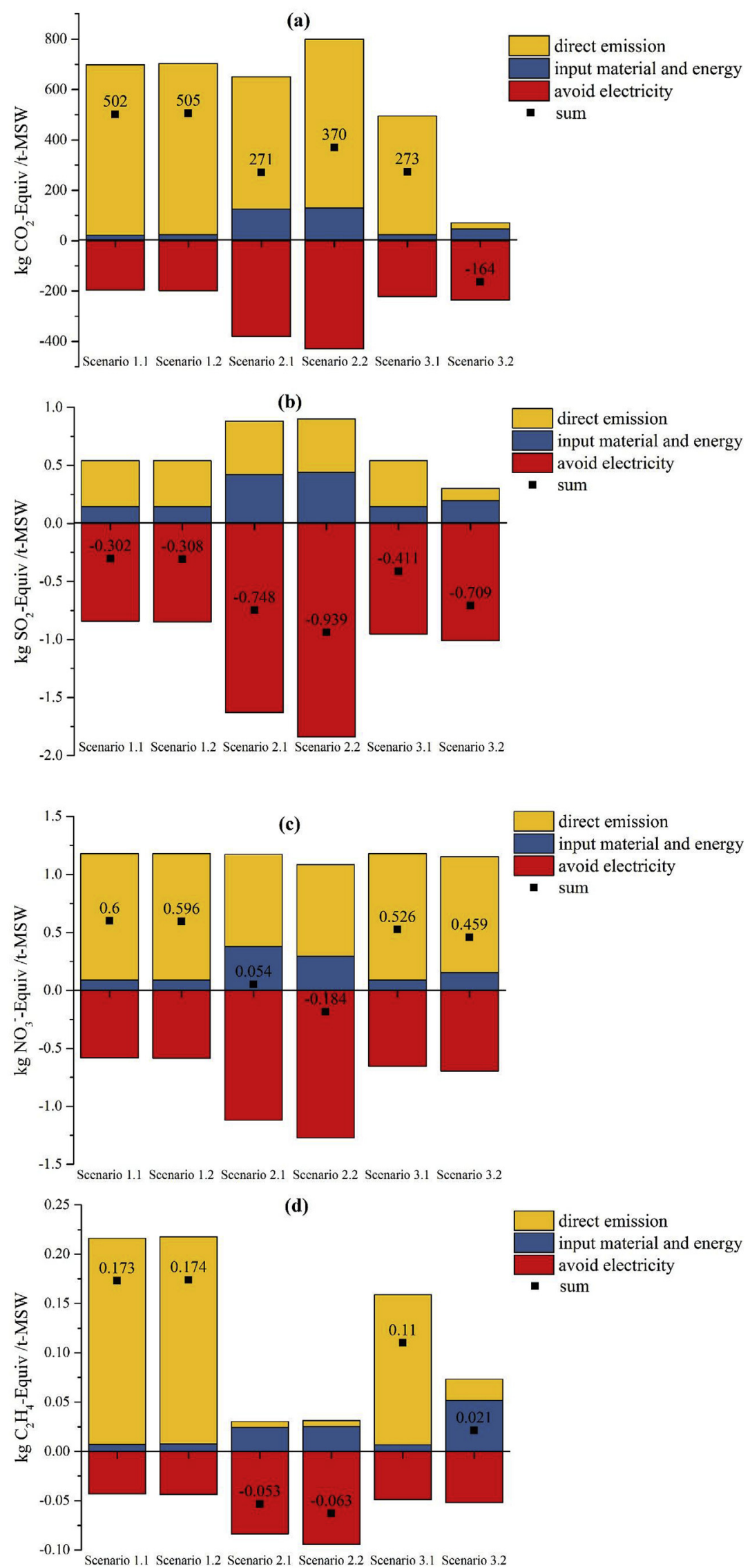

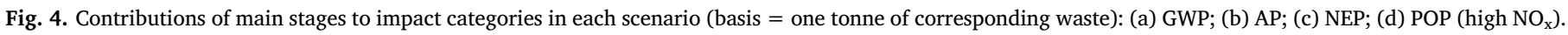




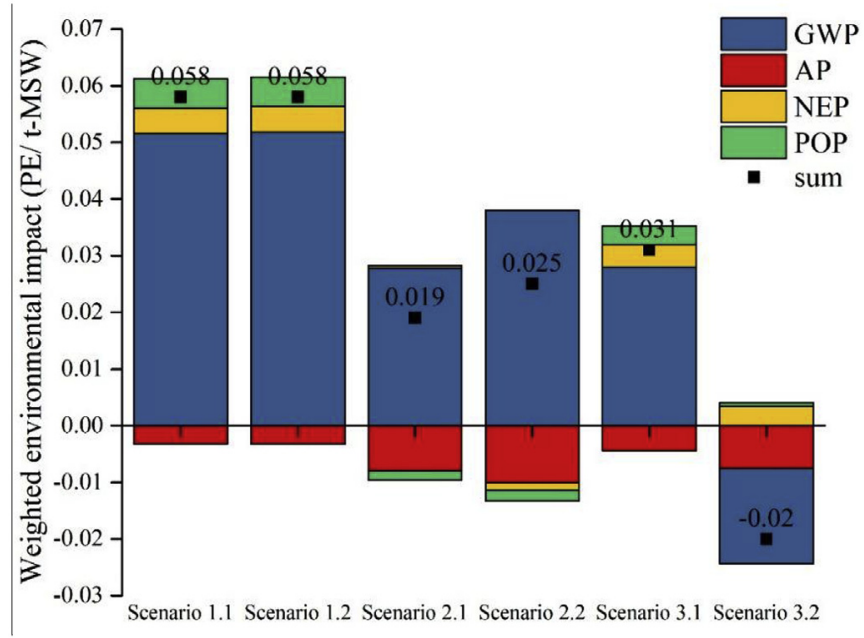

Fig. 5. Weighted environmental impact results of each scenario (basis = one tonne of corresponding waste). PE: One average person equivalent.

performances, while GWP accounting for $88.9 \%$ and $89.3 \%$, respectively. Compared to landfill for mixed waste, separate landfill for food waste reduces $46.6 \%$ of the weighted result. AD scenario shows the best environmental favorability and is the only one achieving a benefit to environment. Incineration scenarios show the best performances in AP, NEP and POP, but high values of GWP. However, GWP is the principle contributor to its weighted results. Thus, incineration scenarios perform worse than $\mathrm{AD}$ scenario, Besides, effective techniques to reduce the GWP are essential for each scenario to the improvement of environmental expression.

\subsection{Environmental performance evolution}

During 2007 to 2016 in Hangzhou, the annual amount of MSW generated was continually increasing and the MSWM system changed a lot, which resulted in the environmental performance evolution (see in Fig. 6). Because of the increase of MSW generated, the annual weighted environmental performance had an overall downward trend. However, there were two special periods with fluctuations: the weighted result dropped $6.1 \%$ from 2009 to 2010 due to implementation of sourceseparated collection; the second period was from 2015 to 2016, with a decline of 4.3\%. During 2015 to 2016, a new incineration plant was put in operation and the growth rate of MSW generated was slow down (only $2.9 \%$ ), leading to a $22.2 \%$ rise of incineration rate. The reduced value by the rise of incineration rate was larger than the added value by the rise of MSW generation. The $\mathrm{AD}$ has the only negative value, but merely accounted for $1.98 \%$ of waste generated in 2016 ; thus, the effect by $\mathrm{AD}$ was little.

Fig. 7 provides details of the integrated MSWM system in impact categories during 2007-2016. Annual GWP value climbed with the rise of annual amount of waste generated, because almost all the scenarios (except scenario 3.2) caused global warming. Unlike to GWP, annual AP value fell from 2007 to 2016 due to the negative values of all scenarios. Annual NEP and POP had the same variation with time. The main reason is that incineration scenario is the only scenario can achieve environmental saving in NEP and POP after source-separated collection. Thus, implementation of source-separated collection and a new incineration plant caused the decline from 2009 to 2010 and from 2015 to 2016 respectively. However, regarding POP, incineration before source-separated collection can also benefit to environment and made a decline from 2008 to 2009 , with the rise of incineration rate, which is different to NEP.

This study also analyzes the annual environmental behavior of integrated MSWM system for treating one tonne of MSW from 2007 to 2016 (see in Fig. 8). The annual weighted result is closely related to the distribution of waste treatment technologies. As shown in Fig. 8, the result went down sharply with the rise of incineration rate from 2007 to 2010. 2010 was a special year with the highest incineration rate and implement of source-separated collection. Because of the limited capacity of incineration plants, the weighted result grew from 2010 to 2013. An AD pilot project was put into operation in 2014 and the weighted result had a little decline from 2013 to 2014. However, the capacity of $\mathrm{AD}$ was so small that its effect was little and the weighted result climbed again with the decline of incineration rate. Then, a new incineration plant resulted in the decline from 2015 to 2016.

The system in 2010 had the best environmental behavior and the weighted result is $0.0349 \mathrm{PE} / \mathrm{t}-\mathrm{MSW}$, while GWP $380 \mathrm{kgCO}_{2}$-Equiv/tMSW, AP -0.645 $\mathrm{kgSO}_{2}$-Equiv/t-MSW, NEP $0.194 \mathrm{kgNO}_{3}$-Equiv/tMSW, and POP $0.041 \mathrm{kgC}_{2} \mathrm{H}_{4}$-Equiv/t-MSW. Besides, the result evolutions of impact categories for treating one tonne of MSW are presented in Fig. A.1SM and they have the similar variation trends as the evolution of weighted result.

\subsection{Sensitivity analysis}

\subsubsection{Capacity of $A D$}

The AD scenario has the best environmental behavior but little effect on the system due to its limited capacity. Therefore, a sensitivity analysis is examined to assess the effect of AD capacity on the environmental results (see in Fig. 9). The system in 2016 is chosen for this analysis and $\mathrm{AD}$ is assumed to have the priority for food waste

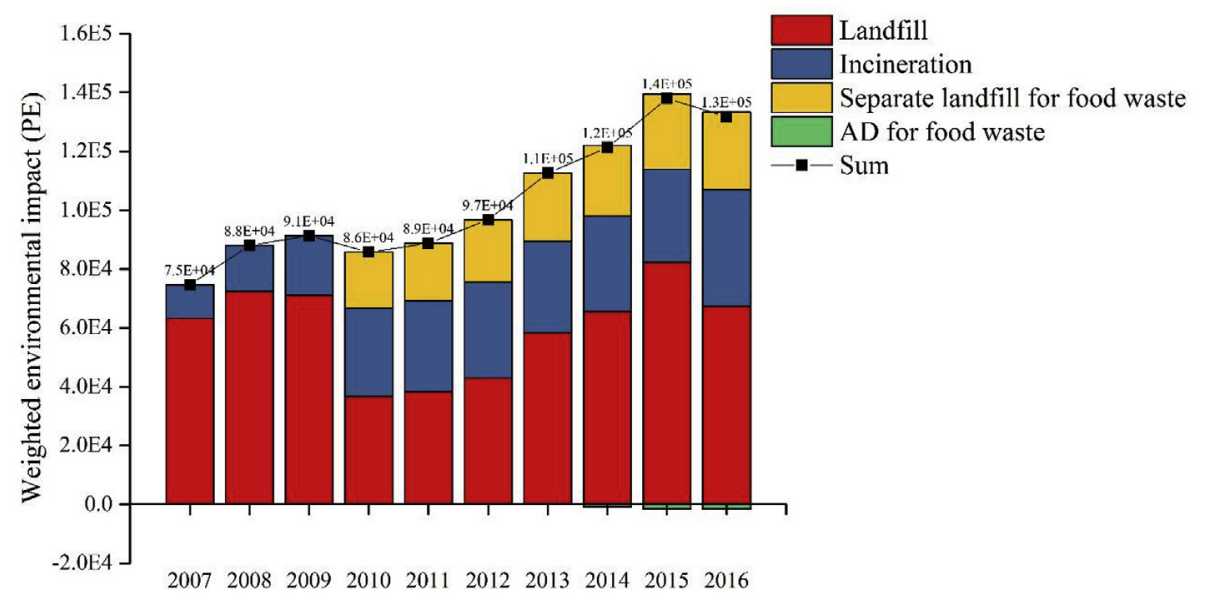

Fig. 6. Evolution of the weighted environmental performance of integrated MSWM system during 2007-2016. 

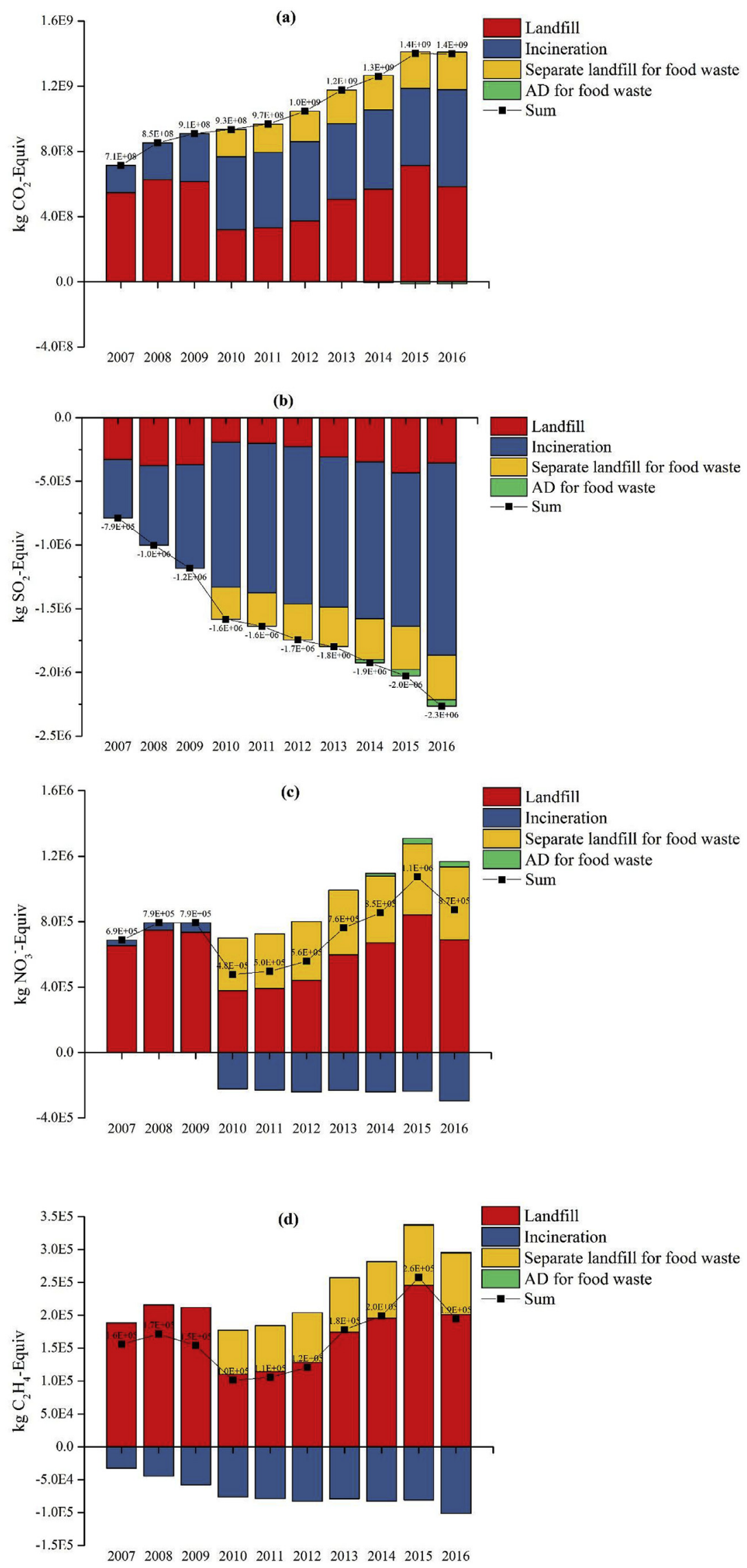

Fig. 7. Evolution of the impact category results of integrated MSWM system during 2007-2016 (a) GWP; (b) AP; (c) NEP; (d) POP. 


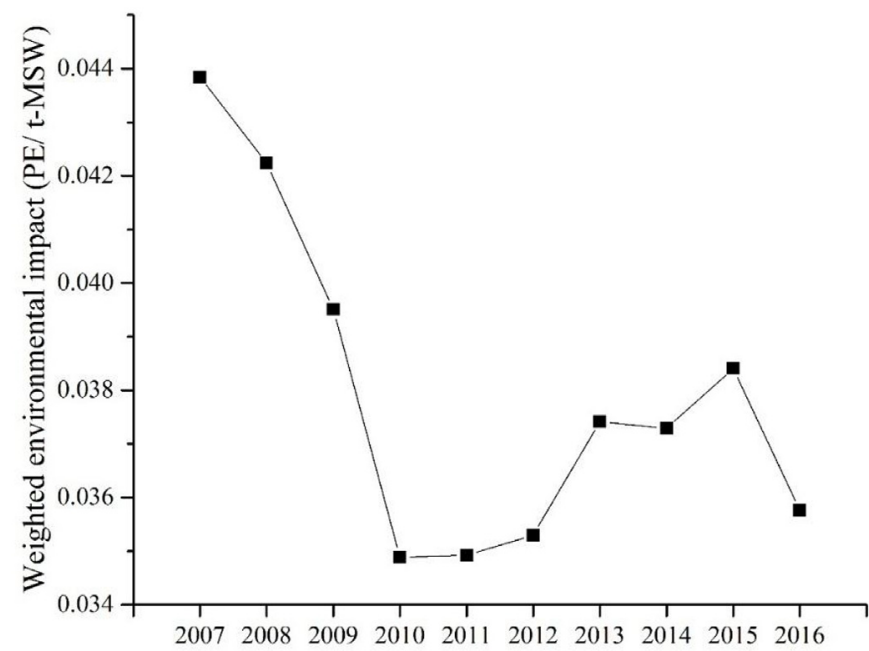

Fig. 8. Evolution of the weighted environmental performance of integrated MSWM system for treating one tonne of MSW during 2007-2016.

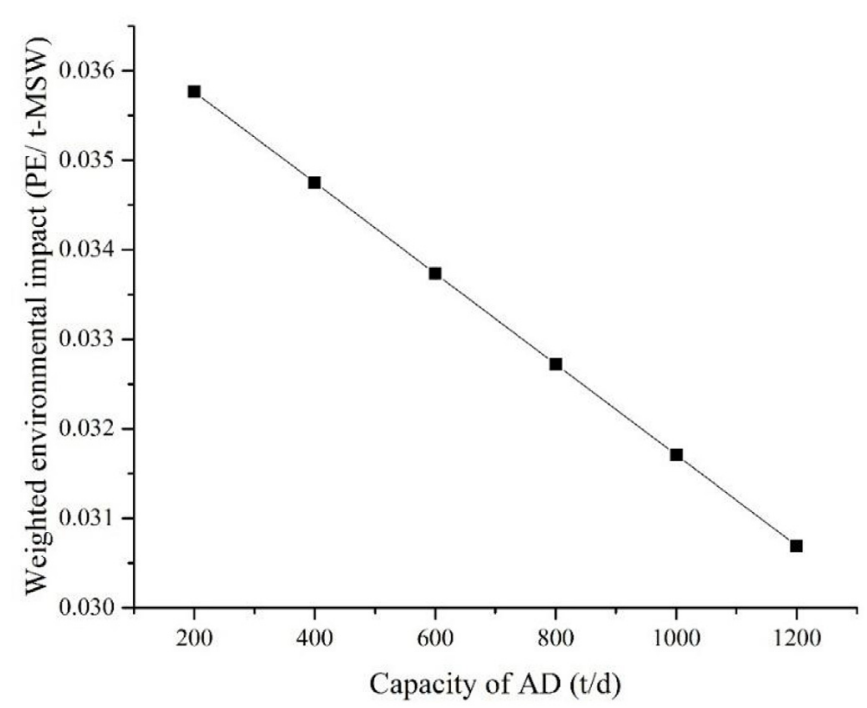

Fig. 9. Environmental performance of integrated MSWM system under different capacities of AD in 2016 (basis = one tonne of MSW).

treatment. The weighted result decreases linearly as the capacity increase. When the capacity of $A D$ reaches $400 \mathrm{t} / \mathrm{d}$, double of current situation, the weighted result is $0.0348 \mathrm{PE} / \mathrm{t}-\mathrm{MSW}$, which is lower than that of the system in 2010. Thus, the AD can improve the MSWM and expanding capacity of AD is highly desired.

\subsubsection{Source-separated collection efficiency}

The environmental performances of MSWM system in 2016 under different source-separated collection efficiencies are examined. As presented in Fig. 10a, weighted result decreases with the source-separation efficiency from $5 \%$ to $45 \%$, but turns to rise as the efficiency exceeds $45 \%$. This phenomenon is because source-separated collection increases the environmental burden of incineration, especially in GWP. Increase in the source-separation efficiency leads to more food waste by separate disposition and less mixed waste by landfill. However, this environmental improvement cannot offset the added burden from incineration when the efficiency is above $45 \%$.

To better check the impact of source-separated collection efficiency, the food waste treatment system is improved and $\mathrm{AD}$ is chosen to substitute separate landfill. Fig. 10b illustrates the sensitivity analysis result of the improved MSWM system. The weighted result decreases sharply as the efficiency increases. The improved MSWM system with $10 \%$ of source-separated collection efficiency show a better environmental performance than the normal system with collection efficiencies from $5 \%$ to $50 \%$. Therefore, the improvement of source-separated collection and food waste treatment system should be paid more attention at the same time.

\subsubsection{Different impact assessment methods}

To check the reliability and robustness of the results, another updated impact assessment method, CML 2001, Jan. 2016 version for world, is adopted. The similar impact categories are considered and both the situations excluding and including biogenic carbon are analyzed. Fig. 11 presents the weighted environmental results of each scenario and the environmental performance evolution by CML 2001 excluding biogenic carbon. It can be concluded that no significant changes are seen between the results by EDIP 97 and CML 2001. Compared to the results by EDIP 97, GWP has smaller proportion of the weighted results by CML 2001 and incineration scenarios become beneficial to environment.

The results by CML 2001 including biogenic carbon are shown in Fig. A.2SM. Because biogenic carbon is considered, the GWP results of scenarios are higher, leading to the higher weighted environmental results and greater environmental burdens. There are no differences on the environmental performance rankings of scenarios and the trends of evolution by different impact assessment methods, which supports the reliability of the results.

\section{Summary}

LCA methodology is adopted in this paper to evaluate the environmental performance evolution of the MSWM system in Hangzhou from 2007 to 2016 . The related data in our study are mainly collected from the long-term on-site visit to waste treatment plants and Hangzhou municipal solid waste disposal supervision center.

It is seen that the annual weighted environmental performance had an overall downward trend with the increase amount of MSW. Regarding treating one tonne of MSW, the weighted result is closely related to the distribution of waste treatment technologies. The MSWM system in 2010 had the best environmental behavior, and this phenomenon was mainly caused by the highest proportion of incineration and implementation of source-separated collection.

Incineration has better environmental impacts than landfill in terms of GWP, AP, NEP and POP, no matter before and after source-separated collection. Thus, based on the annual amount of MSW generated, new incineration plants should be built so that the incineration rate can be increased. In Hangzhou, a new waste-to-energy (WtE) plant (Jiufeng incineration plant) with a capacity of $3000 \mathrm{t} / \mathrm{d}$, was put into trial operation in 2017.

Source-separated collection improves the LHV of MSW and benefits the incineration with more electricity production. Besides, the food waste is disposed separately and less MSW is sent for landfill. The environmental performance of the system obtains an obvious improvement after source-separated collection. However, the source-separated collection policy was just started in China and lags behind its western counterparts. Thus, government should attach importance to sourceseparated collection, and corresponding regulations. Additionally, facilities should be established to enhance the awareness of general public.

Furthermore, sensitivity analysis reveals that food waste treatment plays an important role in the source-separated system. While the importance of source-separated collection is significant, it is also essential to concentrate on the food waste treatment technology. AD can be considered as a primary option for food waste treatment.

In conclusion, this study analyzes the current MSWM system in Hangzhou and the LCA results reflect the effects of MSWM strategies on environmental impacts during 2007-2016. Accordingly, scientific 

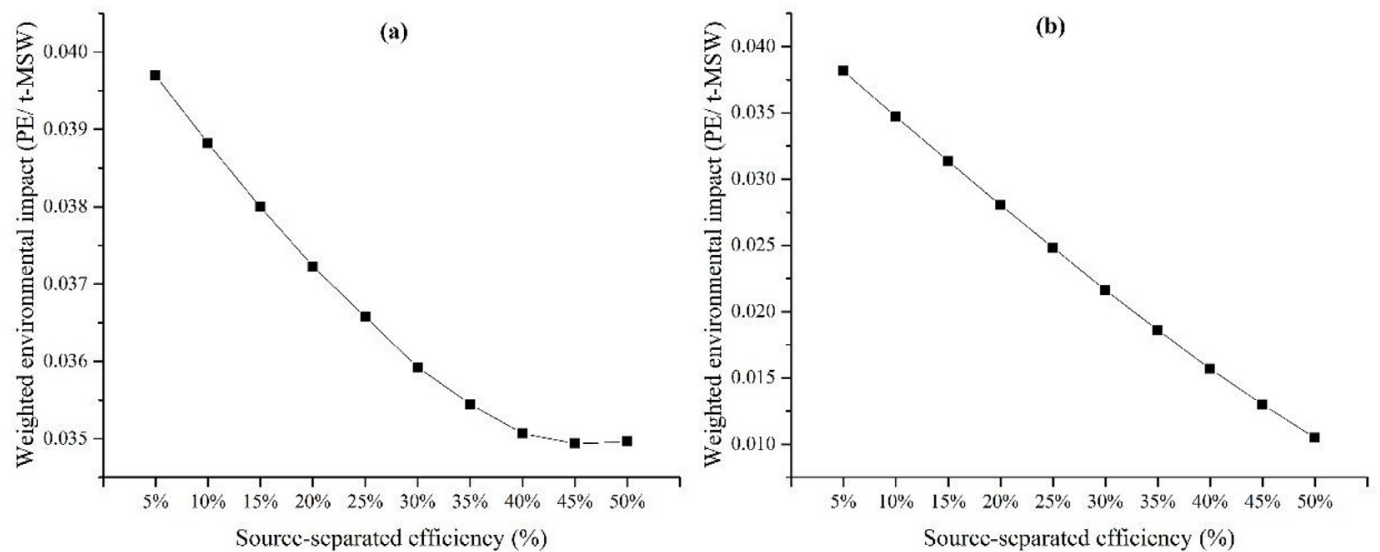

Fig. 10. Environmental performance of integrated MSWM system under different source-separated collection efficiencies in 2016 (basis = one tonne of MSW): (a) the normal MSWM system; (b) the improved MSWM system.
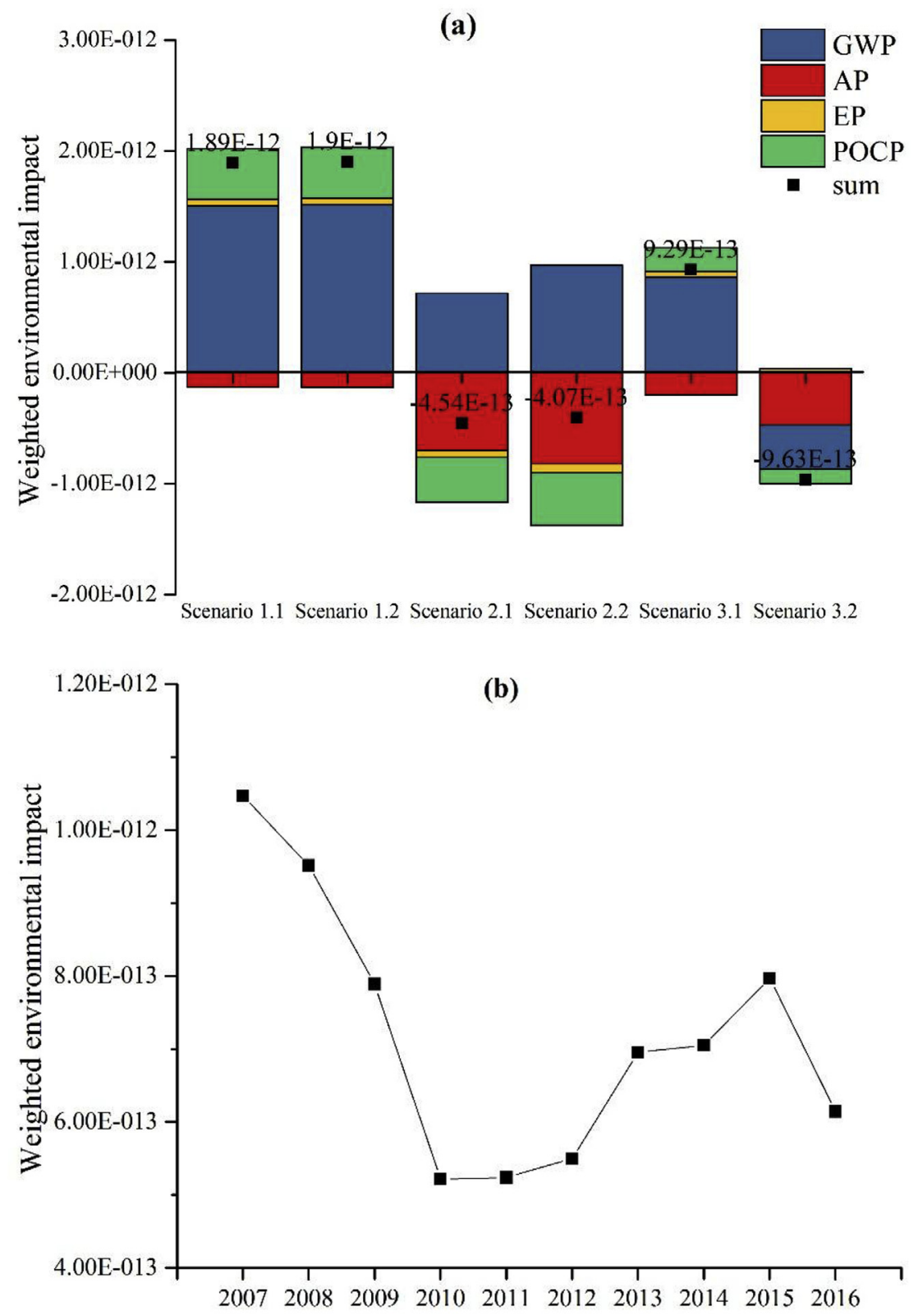

Fig. 11. The environmental results by CML 2001, excluding biogenic carbon (basis = one tonne of MSW): (a) weighted environmental results of each scenario; (b) environmental performance evolution of integrated MSWM system. EP: Eutrophication potential; POCP: Photochem. ozone creation potential; Pt: Point. 
suggestions are provided to benefit the environment for the future MSWM development.

\section{Acknowledgements}

This project is supported by the National Natural Science Foundation of China (No. 51676170) and the Program of Introducing Talents of Discipline to University (B08026).

\section{Appendix A. Supplementary data}

Supplementary data related to this article can be found at https:// doi.org/10.1016/j.jenvman.2018.08.083.

\section{References}

Arena, U., Ardolino, F., Di Gregorio, F., 2015. A life cycle assessment of environmenta performances of two combustion-and gasification-based waste-to-energy technologies. Waste Manag. 41, 60-74.

Astrup, T.F., Tonini, D., Turconi, R., Boldrin, A., 2015. Life cycle assessment of thermal waste-to-energy technologies: review and recommendations. Waste Manag. 37, 104-115.

Chi, Y., Dong, J., Tang, Y., Huang, Q., Ni, M., 2015. Life cycle assessment of municipal solid waste source-separated collection and integrated waste management systems in Hangzhou, China. J. Mater. Cycles Waste Manag. 17, 695-706.

CSYCC (Chinese Statistics Yearbook Compiling Committee), 2016. Chinese statistics yearbook 2015. In: Chinese Statistics Yearbook Compiling Committee. Chinese Statistics Press, Beijing.

Dong, J., Chi, Y., Zou, D., Fu, C., Huang, Q., Ni, M., 2014. Comparison of municipal solid waste treatment technologies from a life cycle perspective in China. Waste Manag. Res. 32, 13-23.

Dong, J., Ni, M., Chi, Y., Zou, D., Fu, C., 2013. Life cycle and economic assessment of source-separated MSW collection with regard to greenhouse gas emissions: a case study in China. Environ. Sci. Pollut. Control Ser. 20, 5512-5524.

Du, R., Qi, B., Guo, H., Shao, B., 2011. Characteristics of atmospheric inversion temperature and its influence on concentration of air pollutants in Hangzhou, Zhejiang Province. J. Meteorol. Environ. 27, 49-53.

Evangelisti, S., Tagliaferri, C., Clift, R., Lettieri, P., Taylor, R., Chapman, C., 2015. Life cycle assessment of conventional and two-stage advanced energy-from-waste technologies for municipal solid waste treatment. J. Clean. Prod. 100, 212-223.

Fruergaard, T., Astrup, T., 2011. Optimal utilization of waste-to-energy in an LCA perspective. Waste Manag. 31, 572-582.

Han, H., Zhang, Z., 2017. The impact of the policy of municipal solid waste source-separated collection on waste reduction: a case study of China. J. Mater. Cycles Waste
Manag. 19, 382-393

Havukainen, J., Zhan, M., Dong, J., Liikanen, M., Deviatkin, I., Li, X., Horttanainen, M., 2017. Environmental impact assessment of municipal solid waste management incorporating mechanical treatment of waste and incineration in Hangzhou, China. J. Clean. Prod. 141, 453-461.

HMSWDSC (Hangzhou Municipal Solid Waste Disposal Supervision Center), 2016. Hangzhou municipal solid waste physical property analysis and disposal method. In: Municipal Solid Waste Disposal Supervision Center, (Hangzhou).

HSYCC (Hangzhou Statistics Yearbook Compiling Committee), 2017. Hangzhou statistics yearbook 2016. In: Hangzhou Statistics Yearbook Compiling Committee. Hangzhou Statistics Press, Hangzhou.

Ibáñez-Forés, V., Bovea, M.D., Coutinho-Nóbrega, C., de Medeiros-García, H.R., BarretoLins, R., 2018. Temporal evolution of the environmental performance of implementing selective collection in municipal waste management systems in developing countries: a Brazilian case study. Waste Manag. 72, 65-77.

IPCC (Intergovernmental Panel on Climate Change), 2006. 2006 IPCC Guidelines for National Greenhouse Gas Inventories. Intergovernmental Panel on Climate Change.

ISO, 2006. ISO 14040 international standard. In: Environmental Management - Life Cycle Assessment - Principles and Framework. International Organisation for Standardization, Geneva, Switzerland.

ISO, 2006. ISO 14044 international standard. In: Environmental Management - Life Cycle Assessment - Requirements and Guidelines. International Organisation for Standardisation, Geneva, Switzerland.

Jeswani, H., Azapagic, A., 2016. Assessing the environmental sustainability of energy recovery from municipal solid waste in the UK. Waste Manag. 50, 346-363.

Jungbluth, N., Chudacoff, M., Dauriat, A., Dinkel, F., Doka, G., Faist Emmenegger, M., Gnansounou, E., Kljun, N., Schleiss, K., Spielmann, M., 2007. Life Cycle Inventories of Bioenergy. Final Report Ecoinvent Data V2. 017

Ma, J., Hipel, K.W., Hanson, M.L., Cai, X., Liu, Y., 2017. An Analysis of Influencing Factors on Municipal Solid Waste Source-separated Collection Behavior in Guilin, China by Using the Theory of Planned Behavior. Sustainable Cities and Society.

Othman, S.N., Noor, Z.Z., Abba, A.H., Yusuf, R.O., Hassan, M.A.A., 2013. Review on life cycle assessment of integrated solid waste management in some Asian countries. J. Clean. Prod. 41, 251-262.

Ripa, M., Fiorentino, G., Vacca, V., Ulgiati, S., 2017. The relevance of site-specific data in Life Cycle Assessment (LCA). The case of the municipal solid waste management in the metropolitan city of Naples (Italy). J. Clean. Prod. 142, 445-460.

Steuer, B., Ramusch, R., Part, F., Salhofer, S., 2017. Analysis of the value chain and network structure of informal waste recycling in Beijing, China. Resour. Conserv. Recycl. 117, 137-150.

Thinkstep, 2018. Gabi 8 Software-system and Database for Life Cycle Engineering, Germany.

Zaman, A., 2013. Life cycle assessment of pyrolysis-gasification as an emerging municipal solid waste treatment technology. Int. J. Environ. Sci. Technol. 10, 1029-1038.

Zhang, H., Wen, Z.-G., 2014. The consumption and recycling collection system of PET bottles: a case study of Beijing, China. Waste Manag. 34, 987-998.

Zhou, Z., Tang, Y., Chi, Y., Ni, M., Buekens, A., 2018. Waste-to-energy: a review of life cycle assessment and its extension methods. Waste Manag. Res. 36, 3-16. 